\title{
Characteristics of vertical air motion in isolated convective clouds
}

\author{
Jing Yang ${ }^{1}$, Zhien Wang ${ }^{1}$, Andrew J. Heymsfield ${ }^{2}$, and Jeffrey R. French ${ }^{1}$ \\ ${ }^{1}$ Department of Atmospheric Science, University of Wyoming, Laramie, WY, USA \\ ${ }^{2}$ National Center for Atmospheric Research, Boulder, CO, USA \\ Correspondence to: Zhien Wang (zwang@uwyo.edu)
}

Received: 15 December 2015 - Published in Atmos. Chem. Phys. Discuss.: 4 February 2016

Revised: 16 July 2016 - Accepted: 22 July 2016 - Published: 11 August 2016

\begin{abstract}
The vertical velocity and air mass flux in isolated convective clouds are statistically analyzed using aircraft in situ data collected from three field campaigns: High-Plains Cumulus $(\mathrm{HiCu})$ conducted over the midlatitude High Plains, COnvective Precipitation Experiment (COPE) conducted in a midlatitude coastal area, and Ice in Clouds Experiment-Tropical (ICE-T) conducted over a tropical ocean. The results show that small-scale updrafts and downdrafts ( $<500 \mathrm{~m}$ in diameter) are frequently observed in the three field campaigns, and they make important contributions to the total air mass flux. The probability density functions (PDFs) and profiles of the observed vertical velocity are provided. The PDFs are exponentially distributed. The updrafts generally strengthen with height. Relatively strong updrafts $\left(>20 \mathrm{~m} \mathrm{~s}^{-1}\right)$ were sampled in COPE and ICE-T. The observed downdrafts are stronger in $\mathrm{HiCu}$ and COPE than in ICE-T. The PDFs of the air mass flux are exponentially distributed as well. The observed maximum air mass flux in updrafts is of the order $10^{4} \mathrm{~kg} \mathrm{~m}^{-1} \mathrm{~s}^{-1}$. The observed air mass flux in the downdrafts is typically a few times smaller in magnitude than that in the updrafts. Since this study only deals with isolated convective clouds, and there are many limitations and sampling issues in aircraft in situ measurements, more observations are needed to better explore the vertical air motion in convective clouds.
\end{abstract}

\section{Introduction}

Convective clouds are an important component of the global energy balance and water cycle because they dynamically couple the planetary boundary layer to the free troposphere through the vertical transport of heat, moisture, and mass (Arakawa, 2004; Heymsfield et al., 2010; Wang and Geerts,
2013). The vertical velocity determines the vertical transport of cloud condensate, the cloud top height, and the detrainment into anvils, which further influences the radiative balance (Del Genio et al., 2005). Vertical velocity also has a significant impact on aerosol activation, droplet condensation, and ice nucleation in convective clouds, which in turn impacts cloud life cycle and precipitation efficiency.

In order to reasonably simulate convective clouds, the vertical air velocity must be parameterized reliably in numerical weather prediction models (NWPMs) and global circulation models (GCMs) (Donner et al., 2001; Tonttila et al., 2011; Wang and Zhang, 2014). However, the complexity of the vertical velocity structure in convective clouds makes the parameterization non-straightforward (Wang and Zhang, 2014). Observations show that in most of convective clouds the vertical velocity is highly variable, and consequently the detailed structure of convection cannot be resolved in many models (Kollias and Albrecht, 2010; Tonttila et al., 2011). Additionally, using the same parameterization of vertical velocity for different grid resolutions may result in different cloud and precipitation properties (Khairoutdinov et al., 2009). Furthermore, poorly parameterized vertical velocity may result in large uncertainties in the microphysics; for instance, the cloud droplet concentration may be underestimated due to unresolved vertical velocity (Ivanova and Leighton, 2008). Vertical velocity simulated by models with horizontal resolutions of a few hundred meters may be more realistic (e.g., Wu et al., 2009), but more observations are needed to evaluate this suggestion.

Aircraft in situ measurement has been the most reliable tool enabling us to understand the vertical velocity in convective clouds and to develop the parameterizations for models. Early studies (e.g., Byers and Braham, 1949; Schmeter, 1969) observed strong updrafts and downdrafts in convec- 
tive clouds; however, their results have large uncertainties because the aircrafts were not equipped with inertial navigation systems (LeMone and Zipser, 1980). In 1974, the Global Atmospheric Research Program (GARP) Atlantic Tropical Experiment (GATE) was conducted off the west coast of Africa, focusing on tropical maritime convections (Houze Jr. and Betts, 1981). A series of findings based on the aircraft data collected from the project were reported. For example, the accumulated probability density functions (PDFs) of vertical velocity and diameter of the convective cores are lognormally distributed. The updrafts and downdrafts in GATE (tropical maritime clouds) were only one half to one third as strong as those observed in the Thunderstorm Project (continental clouds) (LeMone and Zipser, 1980; Houze Jr. and Betts, 1981). These findings stimulated later statistical studies of the vertical velocity in convective clouds. Jorgensen et al. (1985) found that the accumulated PDFs of vertical velocity in intense hurricanes were also distributed lognormally and the strength was similar to that in GATE, but the diameter of the convective region was larger. Studies of convective clouds over Taiwan (Jorgensen and LeMone, 1989) and Australia (Lucas et al., 1994) showed a magnitude of vertical velocity similar to that in GATE. Although the results from the Thunderstorm Project are suspect, the significantly stronger drafts reveal the possible difference between continental and tropical maritime convective clouds. Lucas et al. (1994) suggested that water loading and entrainment strongly reduce the strength of updrafts in maritime convection. However, this underestimation of the updraft intensity may be also due to sampling issues; e.g., penetrations were made outside the strongest cores (Heymsfield et al., 2010).

There are a few more recent aircraft measurements (e.g., Igau et al., 1999; Anderson et al., 2005), but the data are still inadequate to fully characterize the vertical velocity in convective clouds. In most of these earlier papers, the defined draft or draft core required a diameter no smaller than $500 \mathrm{~m}$; this threshold excluded many narrow drafts with strong vertical velocity and air mass flux. In addition, the earlier studies used $1 \mathrm{~Hz}$ resolution data, which, at typical aircraft flight speeds, can resolve only vertical velocity structures larger than a few hundred meters, but the narrow drafts may be important to the total air mass flux exchange and cloud evolution. Furthermore, previous aircraft observations for continental convective clouds were based only on the Thunderstorm Project; thus, additional data are needed to study the difference between continental and maritime convections.

Remote sensing by means of, for example, wind profiling radars is another technique that has often been used in recent years for studying the vertical velocity in convective clouds (e.g., Kollias and Albrecht, 2010; Hogan et al., 2009; Giangrande et al., 2013; Schumacher et al., 2015). Using profiler data, May and Rajopadhyaya (1999) analyzed the vertical velocity in deep convections near Darwin, Australia. They observed that the updraft intensified with height and that the maximum vertical velocity was greater than $15 \mathrm{~m} \mathrm{~s}^{-1}$.
Heymsfield et al. (2010) studied the vertical velocity in deep convection using an airborne nadir-viewing radar. Strong updrafts were observed over both continental and ocean areas, with the peak vertical velocity exceeding $15 \mathrm{~m} \mathrm{~s}^{-1}$ in most of the cases and exceeding $30 \mathrm{~m} \mathrm{~s}^{-1}$ in a few cases. Zipser et al. (2006) used satellite measurements to find the most intense thunderstorms around the world; they applied a threshold updraft velocity greater than $25 \mathrm{~m} \mathrm{~s}^{-1}$ to identify intense convection. Collis et al. (2013) provided statistics of updraft velocities for different convective cases near Darwin, Australia using retrievals from scanning Doppler radars and a multifrequency profiler. Airborne volumetric Doppler radars have also been used to study the dynamic structure of convective clouds (e.g., Jorgensen and Smull, 1993; Hildebrand et al., 1996; Jorgensen et al., 2000). Remote sensing has the advantage of being able to measure the vertical velocity at different heights simultaneously (Tonttila et al., 2011), and some of the techniques can detect the strongest updraft cores in convective clouds (Heymsfield et al., 2010; Collis et al., 2013). Volumetric radars can also provide three-dimensional (3-D) structure of air motion in convective clouds (Collis et al., 2013; Nicol et al., 2015; Jorgensen et al., 2000). However, remote sensing measurements are not as accurate as aircraft measurements because of the assumptions needed to account for the contribution of hydrometeor fall speed in the observed Doppler velocity in order to ultimately estimate air velocity. In addition, ground-based radars can rarely provide good measurements over oceans, and airborne cloud radars often suffer from the attenuation and non-Rayleigh scattering in convective clouds. Therefore, in situ measurements are still necessary in order to characterize the dynamics in convective clouds and to develop parameterizations for models.

The present study provides aircraft data analysis of updrafts and downdrafts in midlatitude continental, midlatitude coastal, and tropical maritime convective clouds using the fast-response in situ measurements collected from three field campaigns: the High-Plains Cumulus ( $\mathrm{HiCu}$ ) project, the COnvective Precipitation Experiment (COPE), and the Ice in Clouds Experiment-Tropical (ICE-T). All data used in this study were compiled for individual, isolated penetrations. Statistics of the vertical velocity and air mass flux are provided. The Wyoming Cloud Radar (WCR), onboard the aircraft, is used to identify the cloud top height, and highfrequency $(25 \mathrm{~Hz})$ in situ measurements of vertical velocity are used to generate the statistics. The major limitations of aircraft in situ measurements are that the aircraft may not be able to sample the strongest convective cores due to safety concern and that it only provides the information of vertical air motion at single levels. These weaknesses need to be kept in mind in the following analyses. Section 2 describes the datasets and wind measuring systems. Section 3 presents the analysis method. Section 4 shows the results. Section 5 discusses the possible factors that interact with vertical air motions, and conclusions are given in Sect. 6. 


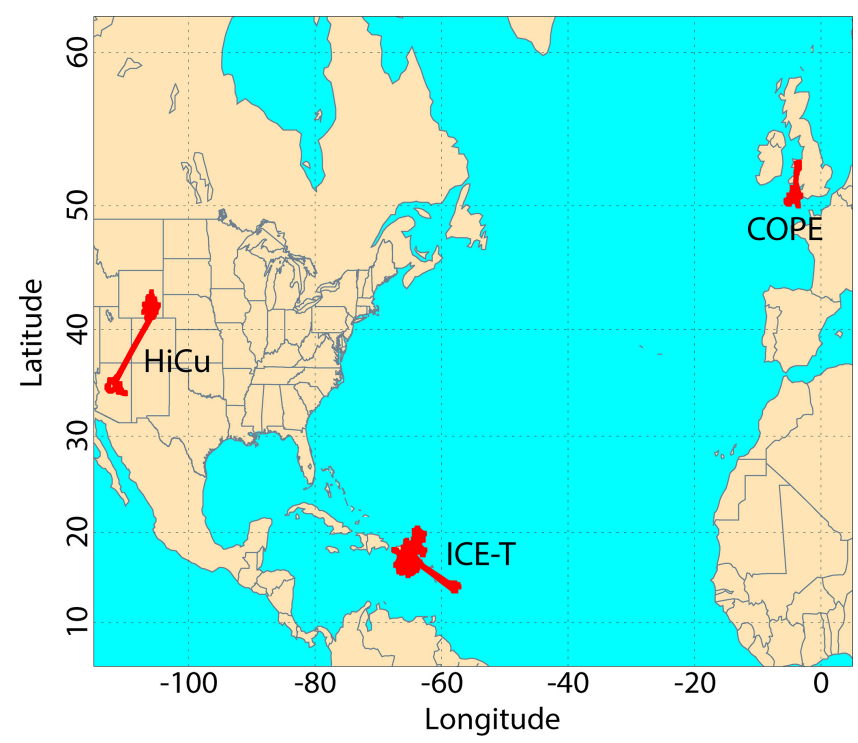

Figure 1. Flight tracks for the three field campaigns: $\mathrm{HiCu}, \mathrm{COPE}$, and ICE-T.

\section{Dataset and instruments}

\subsection{Dataset}

The data used in the present study were collected from three field campaigns: $\mathrm{HiCu}, \mathrm{COPE}$, and ICE-T. Vigorous convective clouds were penetrated during the three field campaigns, including midlatitude continental, midlatitude coastal, and tropical maritime convective clouds. These cloud penetrations provide good-quality measurements for studying the microphysics and dynamics in the convective clouds, as well as the interactions between the clouds and the ambient air. The locations of the three field campaigns are shown in Fig. 1. Information regarding the penetrations used in this study is summarized in Table 1.

The $\mathrm{HiCu}$ project was conducted mainly in Arizona and Wyoming (Fig. 1) from the 18 July to the 5 August 2002, and from the 7 July to the 31 August 2003 to investigate the microphysics and dynamics in convective clouds over the midlatitude High Plains. The University of Wyoming King Air (UWKA) was the aircraft platform used in this project. In 2002 and 2003, 10 and 30 research flights were conducted, respectively. In this study, the $2002 \mathrm{HiCu}$ and $2003 \mathrm{HiCu}$ are analyzed together because they were both conducted over the High Plains and the sample size of $2002 \mathrm{HiCu}$ is relatively small. Fast-response in situ instruments and the WCR (Wang et al., 2012) were operated during the field campaign to measure the ambient environment, cloud dynamics and microphysics and the two-dimensional (2-D) cloud structure. As shown in Table 1, penetrations in $\mathrm{HiCu}$ occurred between 2 and $10 \mathrm{~km}$ above mean sea level (a.m.s.l.) The sample size is relatively large for penetrations below $8 \mathrm{~km}$ and relatively small above $8 \mathrm{~km}$. Accumulated aircraft flight length in cloud was about $2000 \mathrm{~km}$. In situ measurements and WCR worked well in these flights; however, the upward-pointing radar was operated in less than half of the research flights, and thus only a subset of the cloud top heights can be estimated from the observations. Figure $2 \mathrm{a}(1-3)$ show an example of the clouds sampled in $\mathrm{HiCu}$, including WCR reflectivity, Doppler velocity, and $25 \mathrm{~Hz}$ in situ measurement of the vertical velocity. In $\mathrm{HiCu}$, both developing and mature convective clouds were penetrated; some penetrations were near cloud top, while most were more than $1 \mathrm{~km}$ below cloud top. The typical WCR reflectivity ranges from 0 to $15 \mathrm{dBZ}$ in the convective cores. In these clouds, reflectivity is strongly impacted by Mie scattering at the WCR wavelength. From the Doppler velocity and the in situ vertical velocity, we see that, in both the developing and mature cloud, relatively strong updrafts and downdrafts were observed, and multiple updrafts and downdrafts existed in the same cloud. These drafts may be strong for isolated convection but not necessarily strong compared to the strongest updrafts in mesoscale convective systems (MCSs). No balloon soundings are available to measure the ambient environment in $\mathrm{HiCu}$, so we use aircraft measurements to characterize the thermodynamic environment and estimate the convective available potential energy (CAPE). In some cases, the full CAPE cannot be calculated since the aircraft only flew at low levels (below $10 \mathrm{~km}$ a.m.s.l.). The aircraft measurements suggest that the CAPE in $\mathrm{HiCu}$ ranged from less than $100 \mathrm{~J} \mathrm{~kg}^{-1}$ to more than $500 \mathrm{~J} \mathrm{~kg}^{-1}$.

The COPE project was conducted from the 3 July to 21 August 2013 in southwest England (Fig. 1). The UWKA was used to study the microphysics and entrainment in midlatitude coastal convective clouds (Leon et al., 2016). Seventeen research flights were conducted. The penetrations focused on regions near cloud top, which is verified based on the radar reflectivity from the onboard WCR. Since COPE was conducted in a coastal area, the convection initiation mechanism is different from that over a purely continental or ocean area. In addition, although the ambient air mainly came from the ocean, continental aerosols might be brought into the clouds since many of the convective clouds formed within the boundary layer, further impacting the microphysics and dynamics of these clouds. Measurements from COPE include temperature, vertical velocity, liquid water content, and particle concentration and size distributions. The WCR provided measurements of reflectivity and Doppler velocity. The downward Wyoming Cloud Lidar (WCL) was operated to investigate the liquid (or ice) dominated clouds. The typical WCR reflectivity ranged from 5 to $20 \mathrm{dBZ}$ in the convective cores. Between 0 and $6 \mathrm{~km}$, there were about 800 penetrations. Accumulated flight distance in cloud totaled about $1000 \mathrm{~km}$. The sample sizes are relatively large between 2 and $6 \mathrm{~km}$ but relatively small between 0 and $2 \mathrm{~km}$. Examples of the penetrations are given in Fig. $2 \mathrm{~b}(1-$ 3). COPE has fewer penetrations than $\mathrm{HiCu}$, and most of the penetrations are near the cloud top. Figure $2 b(2)$ reveals relatively simple structures of the updrafts and downdrafts 
Table 1. Number of penetrations, time in clouds, and flight length in clouds sampled at $0-2,2-4,4-6,6-8$, and 8-10 km a.m.s.l. in $\mathrm{HiCu}$, COPE, and ICE-T.

\begin{tabular}{|c|c|c|c|c|c|c|c|c|c|}
\hline \multirow{2}{*}{$\begin{array}{r}\text { Height } \\
(\mathrm{km} \text { a.m.s.l. })\end{array}$} & \multicolumn{3}{|c|}{$\mathrm{HiCu}$} & \multicolumn{3}{|c|}{ COPE } & \multicolumn{3}{|c|}{ ICE-T } \\
\hline & $\begin{array}{r}\text { Number of } \\
\text { penetrations }\end{array}$ & $\begin{array}{r}\text { Time in } \\
\text { clouds (min) }\end{array}$ & $\begin{array}{l}\text { Length in } \\
\text { clouds }(\mathrm{km})\end{array}$ & $\begin{array}{r}\text { Number of } \\
\text { penetrations }\end{array}$ & $\begin{array}{r}\text { Time in } \\
\text { clouds (min) }\end{array}$ & $\begin{array}{r}\text { Length in } \\
\text { clouds }(\mathrm{km})\end{array}$ & $\begin{array}{r}\text { Number of } \\
\text { penetrations }\end{array}$ & $\begin{array}{r}\text { Time in } \\
\text { clouds }(\min )\end{array}$ & $\begin{array}{r}\text { Length in } \\
\text { clouds }(\mathrm{km})\end{array}$ \\
\hline $8-10$ & 43 & 12 & 79 & & & & & & \\
\hline 6-8 & 565 & 122 & 789 & & & & 132 & 52 & 423 \\
\hline $4-6$ & 596 & 104 & 653 & 207 & 39 & 244 & 299 & 116 & 895 \\
\hline $2-4$ & 373 & 50 & 274 & 378 & 86 & 486 & 34 & 10 & 73 \\
\hline $0-2$ & & & & 219 & 40 & 211 & 197 & 27 & 167 \\
\hline
\end{tabular}

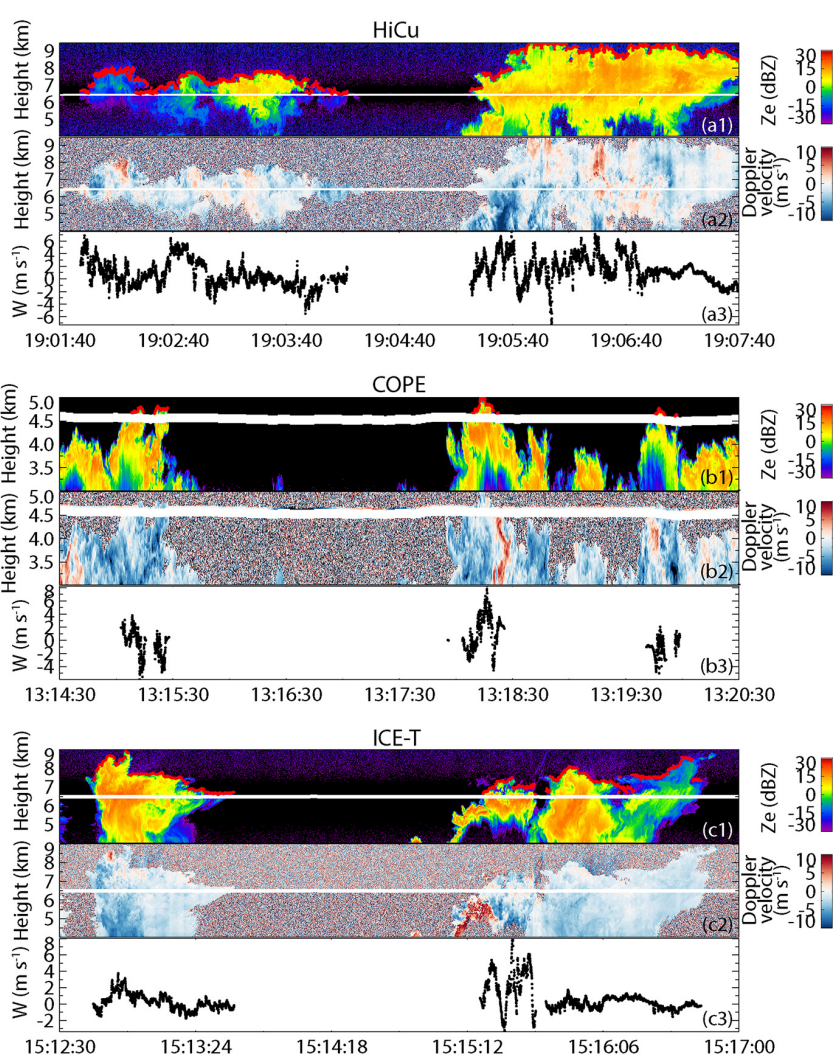

Figure 2. Examples of radar reflectivity, Doppler velocity, and $25 \mathrm{~Hz}$ in situ vertical velocity measurements for the convective clouds sampled in $\mathrm{HiCu}, \mathrm{COPE}$, and ICE-T. The red dots in (a1), (b1), and (c1) are the cloud tops estimated by WCR.

in COPE compared to $\mathrm{HiCu}$, but as shown by the $25 \mathrm{~Hz}$ in situ vertical velocity measurement in Fig. $2 b(3)$, there are still many complicated fine structures in the vertical velocity distribution. The typical CAPE estimated from soundings in COPE was a few hundred $\mathrm{J} \mathrm{kg}^{-1}$.

The ICE-T project was conducted from the 1 July to the 30 July 2011 near St. Croix, U.S. Virgin Islands (Fig. 1), with state-of-the-art airborne in situ and remote sensing instrumentations, with the aim of studying the role of ice generation in tropical maritime convective clouds. The NSF/NCAR C-130 aircraft was used during ICE-T to penetrate convec- tive clouds over the Caribbean Sea. Thirteen C-130 research flights were conducted during the field campaign. In situ measurements from ICE-T include the liquid and total condensed water contents, temperatures, vertical velocities, and cloud and precipitating particle concentrations and size distributions. The WCR was operated on seven research flights to measure the 2-D reflectivity and Doppler velocity fields. Typical WCR reflectivity within convective cores ranged from 10 to $20 \mathrm{dBZ}$. Accumulated flight distance through clouds was greater than $1500 \mathrm{~km}$, throughout the more than 650 penetrations between 0 and $8 \mathrm{~km}$. The sample sizes are good except between 2 and $4 \mathrm{~km}$ (Table 1). Examples of the penetrations are shown in Fig. 2c(1-3). During ICE-T, clouds at different stages were penetrated, including developing, mature, and dissipating clouds, some near cloud top and some considerably below cloud top. Maximum observed updrafts were $25 \mathrm{~m} \mathrm{~s}^{-1}$. Downdrafts in ICE-T were typically weaker than those in $\mathrm{HiCu}$ and COPE. The vertical velocity structures are complicated, as confirmed by both the Doppler velocity and the $25 \mathrm{~Hz}$ in situ measurement. Weak updrafts and downdrafts were also observed in the dissipating clouds. The typical CAPE in ICE-T was greater than $2000 \mathrm{~J} \mathrm{~kg}^{-1}$, which is larger than that in $\mathrm{HiCu}$ and COPE.

During the sampling of isolated convective clouds in all the three field campaigns, the aircraft was typically aligned to penetrate through the center of the convective turret; however, this does not guarantee that the aircraft always penetrated through the strongest updraft at that level. In addition, aircraft in situ measurements only provide the information of vertical air motion at single levels. Moreover, the clouds sampled are isolated convective clouds, MCSs were not sampled. These limitations need to be kept in mind in interpreting the results from the following analyses.

\subsection{Wind measuring system}

On both the C-130 and UWKA, a five-hole gust probe is installed for measurements of 3-D wind. On the C-130, this probe is part of the fuselage radome, on the UWKA the probe is mounted on the end of an extended boom protruding from the front of the aircraft. In both cases the probe contains five pressure ports installed in a "cross" pattern. Relative wind components (e.g., true air speed and flow angles) are 
sensed by a combination of differential pressure sensors attached to the five holes (Wendisch and Brenguier, 2013). Detailed calculation of relative wind components is described in Wendisch and Brenguier (2013). The time response and the accuracy of the pressure sensors is about $25 \mathrm{~Hz}$ and $0.1 \mathrm{mb}$. The 3-D wind vectors are determined by subtracting the aircraft velocity from the relative wind measurement after rotating the vectors to a common coordinate system. On the C-130 and UWKA, aircraft velocity is measured by a Honeywell LASEREF SM Inertial Reference System (IRS), with an accuracy of $0.15 \mathrm{~m} \mathrm{~s}^{-1}$ for vertical motion. Global Positioning System (GPS) was applied to remove the drift errors in the IRS position in all the three field campaigns (Khelif et al., 1999). The final vertical wind velocity product has an accuracy of about $\pm 0.2 \mathrm{~m} \mathrm{~s}^{-1}$ and a time response of $25 \mathrm{~Hz}$. This uncertainty $\left( \pm 0.2 \mathrm{~m} \mathrm{~s}^{-1}\right)$ is a mean bias. For each output, the uncertainty is related to the true air speed, aircraft pitch angle, roll angle, and ambient conditions. Therefore, the random error varies and could be larger than the mean bias. More information about the wind measurement on C-130 and UWKA can be found in the C-130 Investigator Handbook (available on https:/www.eol.ucar.edu/ content/c-130-investigator-handbook) and UWKA Investigator Handbook (available on http://www.atmos.uwyo.edu/ uwka/users/KA_InstList.pdf).

\section{Analysis method}

\subsection{Identifying cloud using in situ measurements}

The Particle Measuring Systems (PMS) Two-Dimensional Cloud (2D-C) Probe and the Forward Scattering Spectrometer Probe (FSSP) are often used to characterize cloud microphysics (e.g., Anderson et al., 2005), although different thresholds of 2D-C and FSSP concentrations are usually used to identify the edge of a cloud. In this paper, we also use FSSP and 2D-C probes to find the cloud edges. In order to find a reasonable threshold for identifying cloudy air, we first use the WCR reflectivity to identify the clouds and the cloudfree atmosphere; for those regions we then plot the particle concentrations measured by FSSP and 2D-C in order to determine reasonable thresholds, and we apply the thresholds of particle concentrations to all the research flights without WCR.

To identify clouds using WCR, the six effective range gates nearest to the flight level (three above and three below) are chosen in each beam. Any beam in which the minimum reflectivity at the six gates exceeds $-30 \mathrm{dBZ}^{1}$ is identified as in-cloud.

\footnotetext{
${ }^{1}$ Based on the reflectivity measured in cloud-free air, the noise level of WCR reflectivity is $-32 \mathrm{dBZ}$ at a range of $500 \mathrm{~m}$ and $-28 \mathrm{dBZ}$ at a range of $1000 \mathrm{~m}$. In this study, we choose $-30 \mathrm{dBZ}$ as the threshold to identify cloud. This threshold $(-30 \mathrm{dBZ})$ is examined for all three field campaigns.
}

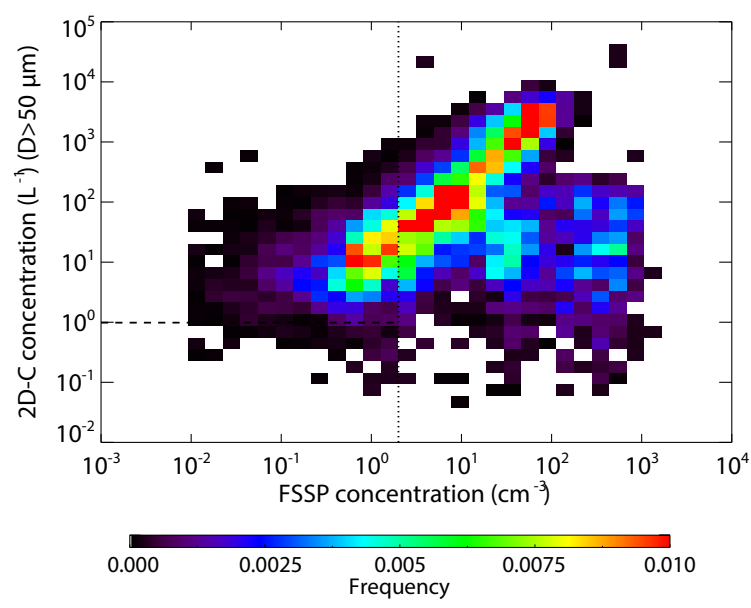

Figure 3. Occurrence distributions as a function of the particle concentrations measured by FSSP versus the concentrations of the particles $\geq 50 \mu \mathrm{m}$ in diameter measured by $2 \mathrm{D}-\mathrm{C}$ in the clouds identified by WCR reflectivity. The dashed and dotted lines indicate the FSSP concentration equal to $2 \mathrm{~cm}^{-3}$ and the 2D-C concentration equal to $1 \mathrm{~L}^{-1}$, respectively.

Figure 3 shows the occurrence distribution as a function of the particle concentrations measured by FSSP versus the concentrations of the particles $\geq 50 \mu \mathrm{m}$ in diameter measured by $2 \mathrm{D}-\mathrm{C}$ in the clouds identified by WCR reflectivity. From the figure, we see that the FSSP concentration ranges from 0.01 to $1000 \mathrm{~cm}^{-3}$, and the $2 \mathrm{D}-\mathrm{C}$ concentration ranges from 0.1 to $10000 \mathrm{~L}^{-1}$. Generally, shallow clouds have relatively higher concentrations of small particles and a lower concentration of particles larger than $50 \mu \mathrm{m}$. In deeper convective clouds, high concentrations can be seen for both small and large particles. The FSSP concentrations in cloud-free air are found to be $2 \mathrm{~cm}^{-3}$ at most, and the FSSP concentrations measured below the lifting condensation level (LCL), where precipitation particles dominated, are lower than $2 \mathrm{~cm}^{-3}$ as well. Therefore, $2 \mathrm{~cm}^{-3}$ is selected as the concentration threshold to identify clouds based on the FSSP measurements, indicated by the dashed line in Fig. 3. However, in some clouds (e.g., pure ice clouds), the FSSP concentration could be lower than $2 \mathrm{~cm}^{-3}$, and 2D-C concentrations are needed to identify these cold clouds. We chose a concentration of $1 \mathrm{~L}^{-1} 2 \mathrm{D}$ $\mathrm{C}$ particles with diameters larger than $50 \mu \mathrm{m}$ as the second threshold to identify cloud, indicated by the dotted line in Fig. 3. In order to avoid precipitating regions (below the LCL calculated from soundings), the second threshold is only applied to penetrations at temperatures colder than $0{ }^{\circ} \mathrm{C}$; thus, the cloud is defined when FSSP concentration $\geq 2 \mathrm{~cm}^{-3}$ or $2 \mathrm{D}-\mathrm{C}$ concentration $\geq 1 \mathrm{~L}^{-1}$. At temperatures warmer than $0{ }^{\circ} \mathrm{C}$, the FSSP concentrations in most convective clouds are higher than $2 \mathrm{~cm}^{-3}$, so only the first threshold is used.

Once a cloud is identified, the penetration details can be calculated, including the flight length, the flight height, the cloud top height if WCR data were available, and the pen- 

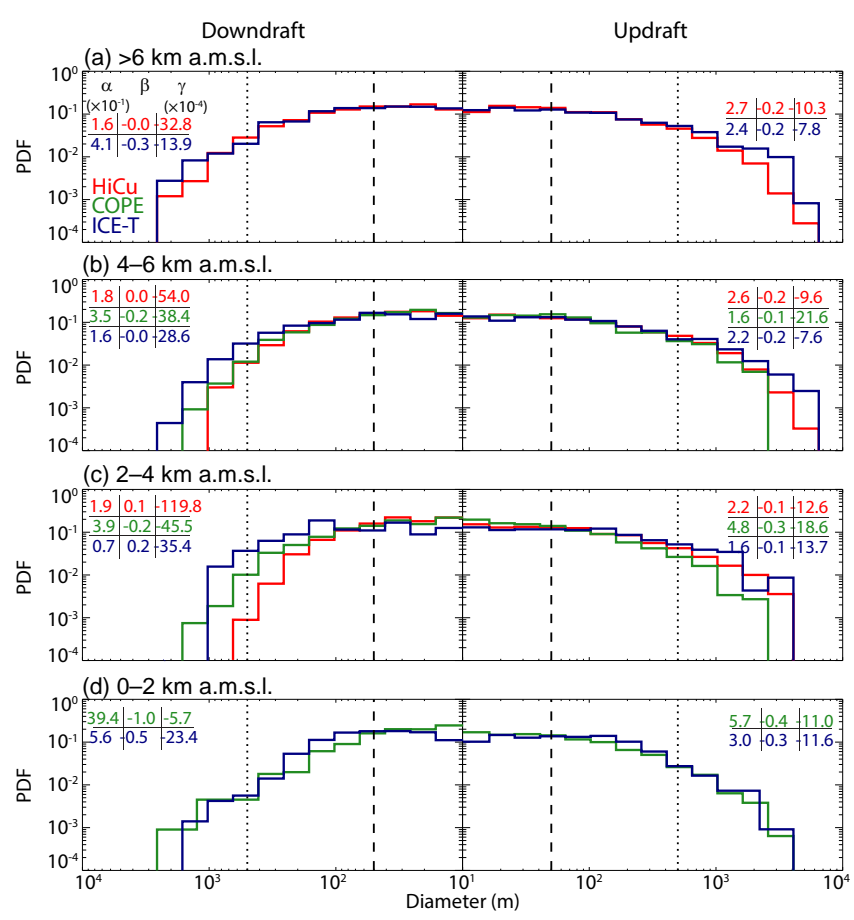

Figure 4. PDFs of the diameters for the updrafts and downdrafts sampled at $0-2,2-4,4-6$, and higher than $6 \mathrm{~km}$. The numbers shown in each panel are the coefficients of the fitted exponential function (Eq. 1).

etration diameter. The penetration diameter is calculated as the distance between the entrance and exit of a penetration. In order to reject penetrations with significant turns, we require that the diameter of a penetration be at least $90 \%$ of the flight length, so the cloud scale will not be significantly overestimated. Since the aircraft might not penetrate exactly through the center of a cloud, the actual cloud diameter may be larger than the penetration diameter. Based on WCR reflectivity images, there are no isolated convective clouds sampled larger than $20 \mathrm{~km}$ in diameter. There are a few penetrations longer than $20 \mathrm{~km}$, but these clouds are more like part of MCSs, and so they are excluded from this study.

\subsection{Defining updraft and downdraft}

In previous studies of the vertical velocity based on in situ measurements, the updraft and downdraft were often defined as an ascending or subsiding air parcel with the vertical velocity continuously $\geq 0 \mathrm{~m} \mathrm{~s}^{-1}$ in magnitude and $\geq 500 \mathrm{~m}$ in diameter (e.g., LeMone and Zipser, 1980; Jorgensen and LeMone, 1989; Lucas et al., 1994; Igau et al., 1999). In this study, we use a vertical velocity threshold of $0.2 \mathrm{~m} \mathrm{~s}^{-1}$; that is, the draft has a vertical velocity continuously $\geq 0.2 \mathrm{~m} \mathrm{~s}^{-1}$ in magnitude because $\pm 0.2 \mathrm{~m} \mathrm{~s}^{-1}$ is the accuracy of the instrument. Any very narrow and weak portion (diameter $<10 \mathrm{~m}$ and maximum vertical velocity $<0.2 \mathrm{~m} \mathrm{~s}^{-1}$ in mag- nitude) between two relatively strong portions is ignored, and the two strong portions are considered as one draft.

The diameter threshold $(500 \mathrm{~m})$ is not used in this paper because drafts narrower than $500 \mathrm{~m}$ frequently occur and they may make important contributions to the total air mass flux in the atmosphere, and therefore they are necessary to be considered in model simulations. Figure 4 shows the PDFs of the diameters of all the updrafts and downdrafts sampled in $\mathrm{HiCu}, \mathrm{COPE}$, and ICE-T. In all the panels, the diameters are exponentially distributed; the PDFs can be fitted using

$f=\alpha \times|x|^{\beta} \times \exp (\gamma|x|)$,

where $f$ is the frequency and $x$ is the diameter. The coefficients $\alpha, \beta$, and $\gamma$ for each PDF are shown in each panel. This function will also be used to fit the PDFs of vertical velocity and air mass flux in the following analyses. Generally, as seen in Fig. 4, the PDFs broaden with increasing height for the three field campaigns, consistent with previous findings (LeMone and Zipser, 1980). The diameters of the observed updrafts are smaller in COPE compared to those sampled in $\mathrm{HiCu}$ and ICE-T, possibly because most of the penetrations are near cloud top. As shown in Fig. 4, many narrow drafts are observed. More than 85, 90, and $74 \%$ of the observed updrafts are narrower than $500 \mathrm{~m}$ (dotted lines) in $\mathrm{HiCu}, \mathrm{COPE}$, and ICE-T, respectively, and more than $90 \%$ of the observed downdrafts in all three field campaigns are narrower than $500 \mathrm{~m}$. A threshold of $500 \mathrm{~m}$ in diameter would exclude many small-scale drafts; therefore, in this study all the drafts broader than $50 \mathrm{~m}$ (dashed lines) are included. Drafts narrower than $50 \mathrm{~m}$ are excluded because most of them are turbulence.

Figure 5a shows the occurrence distributions as a function of the mean vertical velocity versus the diameter of the drafts with the vertical velocity continuously $\geq 0.2 \mathrm{~m} \mathrm{~s}^{-1}$ in magnitude. From the figure, it is noted that many drafts narrower than $500 \mathrm{~m}$ have quite strong vertical velocities. The maximum mean vertical velocity of these narrow drafts can reach $8 \mathrm{~m} \mathrm{~s}^{-1}$, and the minimum mean vertical velocity in the downdrafts is $-6 \mathrm{~m} \mathrm{~s}^{-1}$. With such strong mean vertical velocity, narrow drafts could contribute noticeably to the total air mass flux. Figure $5 \mathrm{~b}$ presents the occurrence distributions as a function of the air mass flux versus the diameter of the drafts. The air mass flux is calculated as $\bar{\rho} \bar{w} D$ (LeMone and Zipser, 1980), where $\bar{\rho}$ is the mean air density at the measurement temperature, $\bar{w}$ is the mean vertical velocity, and $D$ is the diameter of each draft. Due to the limitation of aircraft in situ measurements, the air mass flux is calculated using the data from single-line penetrations. This may introduce additional uncertainties in air mass flux estimations for these clouds. Figure 5b shows that the air mass flux in many drafts narrower than $500 \mathrm{~m}$ is actually larger than air mass flux in some of the broader drafts. The maximum value for these narrow updrafts reaches $4000 \mathrm{~kg} \mathrm{~m}^{-1} \mathrm{~s}^{-1}$, and the minimum value for the downdrafts reaches $-3000 \mathrm{~kg} \mathrm{~m}^{-1} \mathrm{~s}^{-1}$. The normalized accumulated flux (red curves) reveals that 


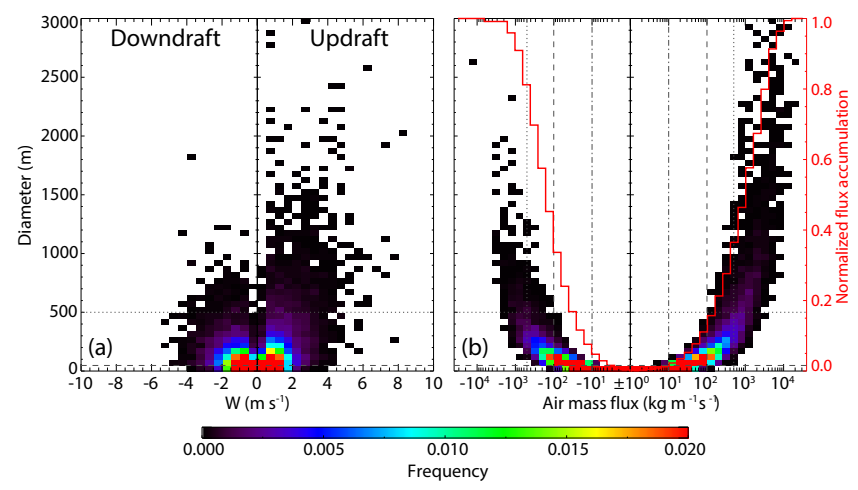

Figure 5. Occurrence distributions as (a) a function of diameter and mean vertical velocity and (b) a function of diameter and air mass flux for all updrafts and downdrafts. The normalized accumulation flux is also shown by the red curves. The horizontal dotted and dashed lines in (a) and (b) indicate the draft diameter equal to 500 and $50 \mathrm{~m}$, which are used as the diameter thresholds to identify a "draft" in previous studies and in this study, respectively. The vertical dash-dotted, dashed, and dotted lines in (b) indicate air mass flux equal to 10,100 , and $500 \mathrm{~kg} \mathrm{~m}^{-1} \mathrm{~s}^{-1}$ in magnitude, respectively, which are the thresholds used to delineate the three different groups of draft.

the drafts narrower than $500 \mathrm{~m}$ (dotted horizontal lines) contribute significantly to the total air mass flux. Calculations indicate that the updrafts narrower than $500 \mathrm{~m}$ contribute 20 $35 \%$ of the total upward flux, and that the downdrafts narrower than $500 \mathrm{~m}$ contribute $50-65 \%$ of the total downward air mass flux. Drafts narrower than $50 \mathrm{~m}$ (dashed horizontal lines), which are excluded in this paper, contribute less than $5 \%$ of the total air mass flux.

In this study, we delineate three different groups of updrafts and downdrafts using three thresholds of air mass flux: 10,100 , and $500 \mathrm{~kg} \mathrm{~m}^{-1} \mathrm{~s}^{-1}$ in magnitude. The air mass flux is used here to delineate the draft intensity because (1) air mass flux contains the information of both vertical velocity and draft size, (2) air mass flux can reveal the vertical mass transport through convection, and (3) air mass flux is an important component in cumulus and convection parameterizations (e.g., Tiedtke, 1989; Bechtold et al., 2001). The first designated group, the "weak draft," with air mass flux $10-100 \mathrm{~kg} \mathrm{~m}^{-1} \mathrm{~s}^{-1}$ in magnitude, contributes $10 \%$ of the total upward air mass flux and $10 \%$ of the total downward air mass flux. The "moderate draft," with air mass flux $100-500 \mathrm{~kg} \mathrm{~m}^{-1} \mathrm{~s}^{-1}$ in magnitude, contributes $25 \%$ of the total upward air mass flux and $40 \%$ of the total downward air mass flux. The "strong draft", in which the air mass flux $\geq 500 \mathrm{~kg} \mathrm{~m}^{-1} \mathrm{~s}^{-1}$ in magnitude, contributes $60 \%$ of the total upward air mass flux and $20 \%$ of the total downward air mass flux. The definitions of "weak", "moderate", and "strong" only apply for the isolated convective clouds analyzed in this study and are not necessarily appropriate for organized convection (e.g., MCS). Drafts weaker than
$10 \mathrm{~kg} \mathrm{~m}^{-1} \mathrm{~s}^{-1}$ are not analyzed because they are too weak and most of them are very narrow (Fig. 5b). The numbers of weak, moderate, and strong updrafts and downdrafts sampled at $0-2,2-4,4-6,6-8$, and $8-10 \mathrm{~km}$ a.m.s.l. are shown in Table 2. Generally, weak and moderate drafts are more often observed than strong drafts. At most of the height ranges, more updrafts are observed than downdrafts.

Some researchers have defined a "draft core" by selecting the strongest portion within a draft. For example, LeMone and Zipser (1980) define an updraft core as an ascending air motion with vertical velocity continuously $\geq 1 \mathrm{~m} \mathrm{~s}^{-1}$ and diameter $\geq 500 \mathrm{~m}$. This definition of a draft core is followed in a few more recent studies (e.g., Jorgensen and LeMone, 1989; Lucas et al., 1994; Igau et al., 1999). We too analyzed the vertical air motion characteristics in the stronger portion of the drafts considered here. However, we found that in many updrafts the strong portion where the vertical velocity is continuously $\geq 1 \mathrm{~m} \mathrm{~s}^{-1}$ dominates and contributes $80 \%$ of the total air mass flux, so the statistics of the vertical air motion characteristics in the stronger portion are very similar to those in the draft as a whole. Therefore, the present study focuses on drafts in which both weak and strong portions are included.

\section{Results}

\subsection{Significance of drafts in different strengths}

From the analysis above, we note that relatively small and weak updrafts are frequently observed in convective clouds. In this section, we provide further evidence to show the importance of the relatively weak updrafts in terms of air mass flux.

Figure 6a shows the average number of updrafts as a function of air mass flux observed in the three field campaigns. The solid, dashed, and dotted lines represent the penetrations with different diameters. As shown in Fig. 6a, weak and moderate updrafts are more often observed than strong updrafts, and more updrafts are observed in longer penetrations. Since this is an average result, the number of updrafts could be smaller than 1 (e.g., many short penetrations do not have strong updrafts). Figure $6 \mathrm{~b}$ is similar to $6 \mathrm{a}$ but shows the occurrence frequency of updrafts with different air mass fluxes (i.e., the vertical axis in Fig. 6a is normalized). For the penetrations less than $1 \mathrm{~km}$ in length, many of the clouds only have weak or moderate updrafts, and relatively strong updrafts are rarely observed. For penetrations of $1-10 \mathrm{~km}$, the frequency of strong updrafts increases and the frequency of weak and moderate updrafts decreases. For even longer penetrations $(>10 \mathrm{~km})$, however, the frequency of weak updrafts increases again, indicating the increasing importance of weak updrafts.

Figure 7 shows the average percentile contributions to the total upward air mass flux by the three different groups of 
Table 2. Number of updrafts and downdrafts sampled at $0-2,2-4,4-6,6-8$, and $8-10 \mathrm{~km}$ in HiCu, COPE, and ICE-T. Three numbers are given for the updraft and downdraft at each level, according to the three different definitions: weak, moderate, and strong.

\begin{tabular}{|c|c|c|c|c|c|c|c|}
\hline \multicolumn{2}{|c|}{ Height (km) } & \multicolumn{2}{|c|}{$\mathrm{HiCu}$} & \multicolumn{2}{|c|}{ COPE } & \multicolumn{2}{|c|}{ ICE-T } \\
\hline & & Updraft & Downdraft & Updraft & Downdraft & Updraft & Downdraft \\
\hline \multirow[t]{3}{*}{$8-10$} & Weak & 66 & 100 & & & & \\
\hline & Moderate & 52 & 44 & & & & \\
\hline & Strong & 44 & 17 & & & & \\
\hline \multirow[t]{3}{*}{$6-8$} & Weak & 818 & 763 & & & 382 & 372 \\
\hline & Moderate & 559 & 540 & & & 175 & 136 \\
\hline & Strong & 287 & 130 & & & 102 & 23 \\
\hline \multirow[t]{3}{*}{$4-6$} & Weak & 748 & 668 & 290 & 184 & 858 & 671 \\
\hline & Moderate & 522 & 389 & 232 & 193 & 425 & 329 \\
\hline & Strong & 343 & 48 & 135 & 51 & 266 & 73 \\
\hline \multirow[t]{3}{*}{$2-4$} & Weak & 311 & 235 & 568 & 424 & 49 & 47 \\
\hline & Moderate & 271 & 84 & 467 & 434 & 51 & 51 \\
\hline & Strong & 149 & 7 & 188 & 101 & 32 & 10 \\
\hline \multirow[t]{3}{*}{$0-2$} & Weak & & & 368 & 192 & 319 & 205 \\
\hline & Moderate & & & 266 & 90 & 234 & 104 \\
\hline & Strong & & & 96 & 9 & 60 & 7 \\
\hline
\end{tabular}
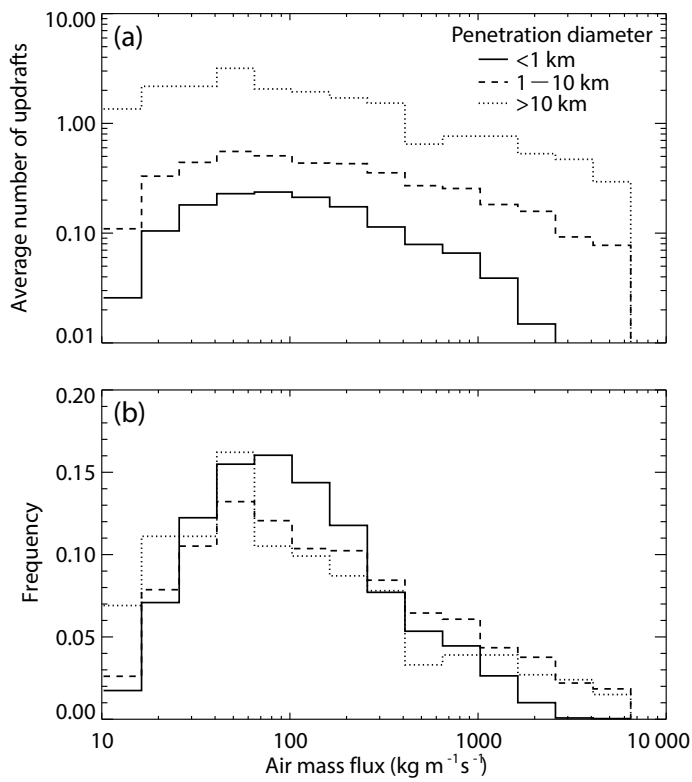

Figure 6. (a) Average number and (b) occurrence frequency of updrafts as a function of air mass flux observed in penetrations with length $<1 \mathrm{~km}$ (solid), 1-10 km (dashed), and $>10 \mathrm{~km}$ (dotted). The result is a composite of $\mathrm{HiCu}, \mathrm{COPE}$, and ICE-T.

updrafts as a function of penetration diameter. In Fig. 7a, all the penetrations are included. Since many narrow clouds have no strong updrafts in terms of air mass flux, the total air mass flux in these narrow clouds is mostly contributed by weak (red bar) and moderate (green bar) drafts. These narrow clouds may have a large vertical velocity but small air mass flux. As the diameter increases to $4 \mathrm{~km}$, the contributions to total air mass flux from relatively weak updrafts (red bar) decrease, while those from stronger updrafts (blue bar) increase. For a penetration of $4 \mathrm{~km}$ length, $80-90 \%$ of the total upward mass flux is contributed by the strong updrafts with air mass flux $\geq 500 \mathrm{~kg} \mathrm{~m}^{-1} \mathrm{~s}^{-1}$. However, for the penetrations with a diameter larger than $4 \mathrm{~km}$, the contribution from relatively weak updrafts increases, probably because more weak updrafts exist in wider clouds (Fig. 6). This is more obvious in Fig. 7b, in which only the penetrations with at least one strong updraft are included. As the diameter increases from $400 \mathrm{~m}$ to $20 \mathrm{~km}$, the contribution from the weak and moderate updrafts (red bars and green bars) increases from 2 to $20 \%$. This suggests that as the cloud evolves and becomes broader (e.g., mature or dissipating stage), the weak and moderate updrafts are also important and therefore necessary to be considered in model simulations.

\subsection{PDFs of vertical velocity and air mass flux}

Figure 8 shows the PDFs of the vertical velocity in the drafts sampled at $0-2,2-4$, and $4-6 \mathrm{~km}$ and higher than $6 \mathrm{~km}$ in the three field campaigns. Columns (a), (b), and (c) represent the drafts with air mass flux $\geq 10, \geq 100$, and $\geq 500 \mathrm{~kg} \mathrm{~m}^{-1} \mathrm{~s}^{-1}$ in magnitude, respectively; in other words, column (a) includes all the weak, moderate, and strong of drafts, column (b) includes moderate and strong updrafts, and column (c) includes strong updrafts only. For statistical analysis, it is better to analyze different drafts together rather than separately. Since the aircraft might under-sample the strongest updraft cores, the tails of the PDFs could be biased low, but these PDFs still provide valuable information. In all the panels, the observed vertical velocities are exponentially distributed for both updrafts and downdrafts; the PDFs can be fitted using Eq. (1). From Fig. 8 we see that at $0-2 \mathrm{~km}$, the PDFs for both 
COPE and ICE-T are narrow. At $2-4 \mathrm{~km}$, stronger updrafts and broader PDFs are observed in both COPE and ICE-T compared to those at $0-2 \mathrm{~km}$, and the maximum vertical velocity is about $15 \mathrm{~m} \mathrm{~s}^{-1}$. In COPE, the observed downdrafts are stronger than those in ICE-T, with the minimum vertical velocity as low as $-10 \mathrm{~m} \mathrm{~s}^{-1}$. For $\mathrm{HiCu}$, the PDFs of the vertical velocity at $2-4 \mathrm{~km}$ are narrow because the $\mathrm{HiCu}$ project was conducted in the High Plains and the cloud bases were relatively high. At $4-6 \mathrm{~km}$, the observed updrafts become stronger and the PDFs become broader in all the three field campaigns compared to those at lower levels, especially for COPE and ICE-T. Above $6 \mathrm{~km}$, the PDFs for the updraft become broader in $\mathrm{HiCu}$ while they slightly narrow in ICE-T compared to those at 4-6 km. For the observed downdrafts, the PDFs broaden with height for all the three field campaigns. Generally, the PDFs of the vertical velocity are similar for the three columns. The main difference is found in the first bins of the vertical velocity $\left(0-2\right.$ and -2 to $\left.0 \mathrm{~m} \mathrm{~s}^{-1}\right)$ : highest for column (a), which includes all the drafts with air mass flux $\geq 10 \mathrm{~kg} \mathrm{~m}^{-1} \mathrm{~s}^{-1}$ in magnitude, and lowest for column (c), which only includes the strong drafts with air mass flux $\geq 500 \mathrm{~kg} \mathrm{~m}^{-1} \mathrm{~s}^{-1}$ in magnitude.

In Fig. 8, the observed updrafts are stronger in ICE-T and COPE (maritime or coastal convective clouds) than in $\mathrm{HiCu}$ (pure continental convective clouds). But the aircraft might under-sample the strongest part of the convective cores. In addition, the PDFs are plotted as a function of mean sea level height, the relatively narrow PDFs in $\mathrm{HiCu}$ compared to COPE and ICE-T at the same height are possibly because of the higher cloud bases in $\mathrm{HiCu}$. Other than the sampling issues, the triggering mechanism for convection is also important for the updraft strength. The clouds sampled in the three field campaigns are all isolated convective clouds, the CAPE in HiCu was smaller than in COPE and ICE-T. Compared to the GATE project, in which the clouds were also sampled over a tropical ocean, the PDFs of the vertical velocity in ICE-T have a similar vertical dependence, broadening with height. But the PDFs are broader in ICE-T than those in GATE, and the maximum vertical velocity $\left(25 \mathrm{~m} \mathrm{~s}^{-1}\right)$ in ICE-T is greater than that observed in GATE $\left(15 \mathrm{~m} \mathrm{~s}^{-1}\right)$. In GATE, the in situ measurements also have sampling issues. More measurements are needed to further evaluate the difference between maritime and continental convective clouds.

Figure 9 shows the PDFs of the air mass flux for all the drafts sampled at 0-2, 2-4, and 4-6 km and higher than $6 \mathrm{~km}$. The PDFs are exponentially distributed for the three field campaigns at different heights, which can be fitted using Eq. (1). The coefficients for the fitted function are shown in each panel. In the three field campaigns, the PDFs of air mass flux have no obvious trend with height, although the PDFs of diameter and vertical velocity broaden with height. The differences among the three field campaigns are small for weak and moderate drafts, and become slightly larger for relatively strong updrafts, which could be due to the sampling issues.
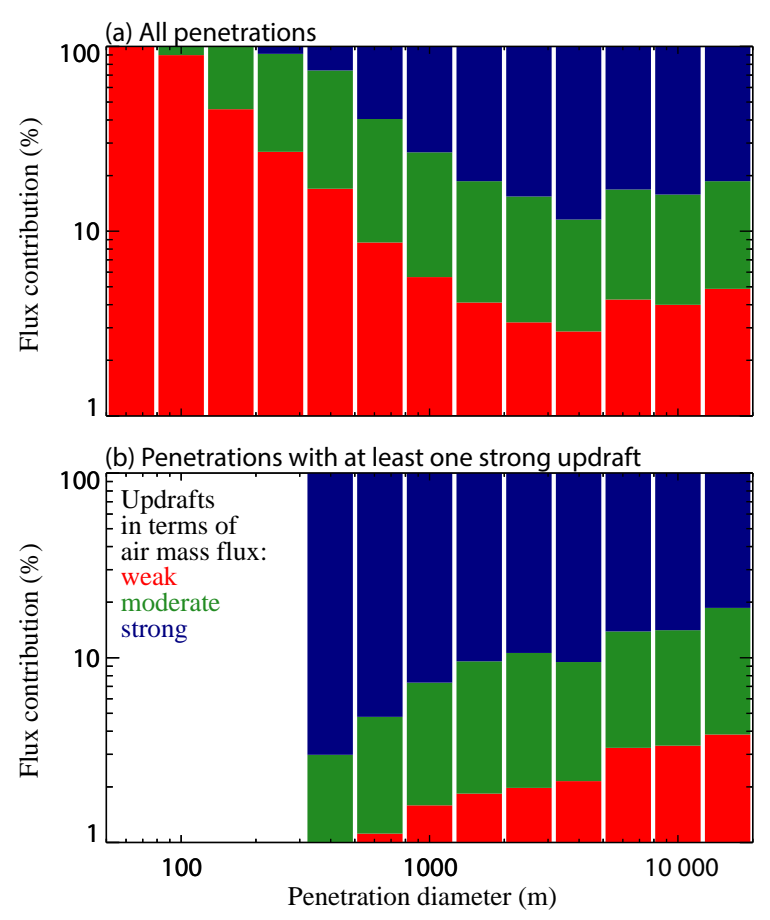

Figure 7. Average percentile contribution to total upward air mass flux by the weak (red), moderate (green), and strong (blue) updrafts delineated in this study. The result is a composite of $\mathrm{HiCu}, \mathrm{COPE}$, and ICE-T.

\subsection{Profiles of vertical velocity and air mass flux}

Figure 10 is a whisker-box plot showing the profiles of the vertical velocity $(\mathrm{a}-\mathrm{c})$ and air mass flux $(\mathrm{d}-\mathrm{f})$ in the drafts based on the three defined thresholds of air mass flux. The solid box includes all three different groups of drafts, the dashed boxes excludes the weak drafts, and the dotted boxes includes strong drafts. The minimum, 10, 50, $90 \%$, and maximum values are shown in each box. In each panel, the absolute values of the vertical velocities and air mass flux (except the minimum and maximum ones) are relatively small for the solid boxes.

In Fig. $10 \mathrm{a}-\mathrm{c}$, the three definitions of drafts show different intensities in the vertical velocities. Typically, the 10,50, and $90 \%$ values in the dotted boxes are 1-2 times larger in magnitude than those in the solid boxes. However, the profiles of the three definitions of drafts vary similarly with height for each field campaign. In the updrafts sampled during $\mathrm{HiCu}$ (Fig. 10a), the maximum vertical velocity increases with height up to $8 \mathrm{~km}$, then decreases with height above that. The $90 \%$ vertical velocity in the solid boxes increases from 4 to $8 \mathrm{~m} \mathrm{~s}^{-1}$ between 0 and $10 \mathrm{~km}$. The 10 and $50 \%$ vertical velocities in the solid boxes remain similar between 2 and $8 \mathrm{~km}$, then slightly increase at $8-10 \mathrm{~km}$. In the downdrafts, the minimum vertical velocity decreases from $-7 \mathrm{~m} \mathrm{~s}^{-1}$ to $-12 \mathrm{~m} \mathrm{~s}^{-1}$ up to $8 \mathrm{~km}$ and increases to $-9 \mathrm{~m} \mathrm{~s}^{-1}$ at $8-10 \mathrm{~km}$. The 10, 50, and $90 \%$ values all slightly decrease with height. 


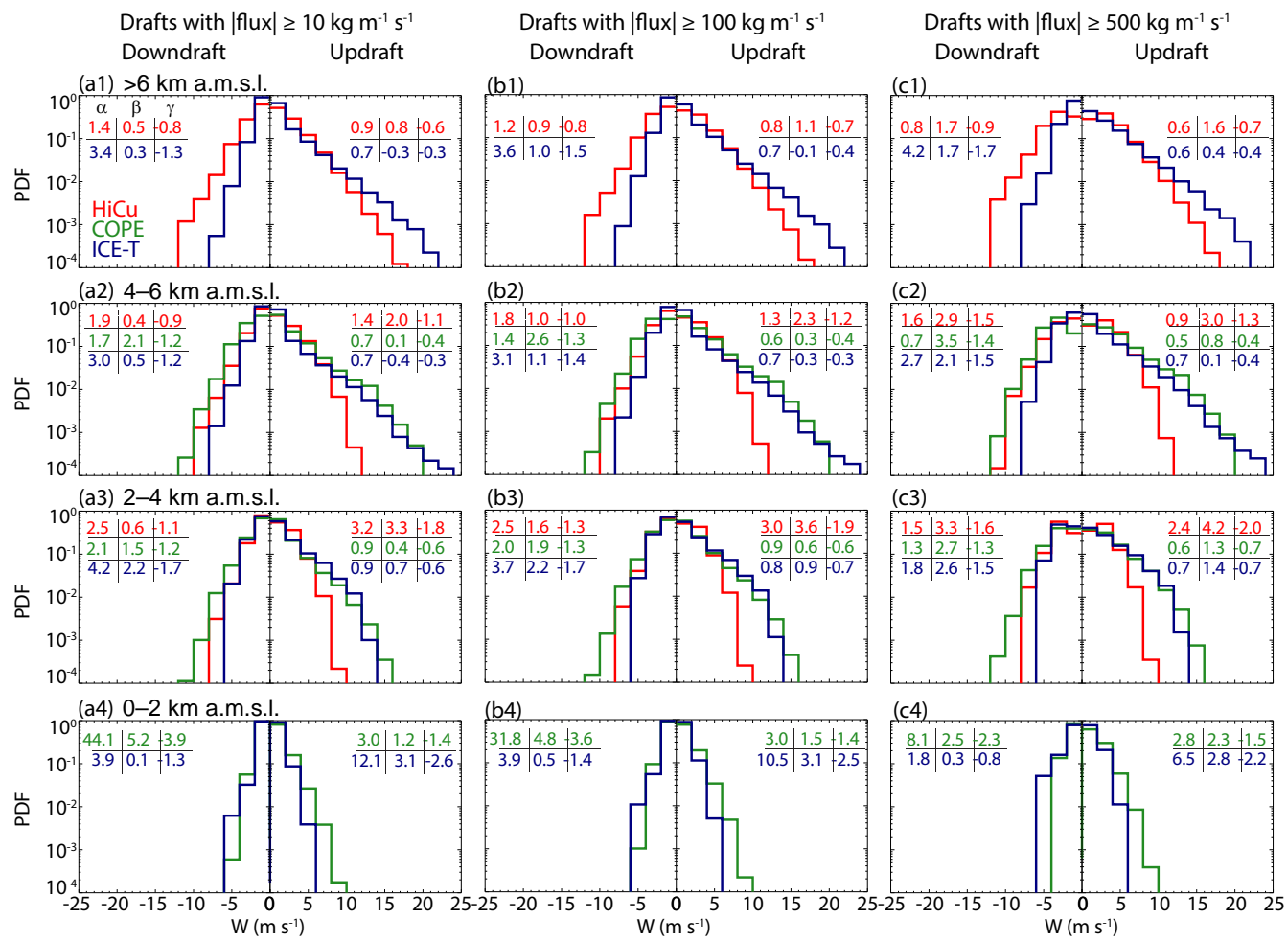

Figure 8. PDFs of the $25 \mathrm{~Hz}$ vertical velocity for the updrafts and downdrafts with air mass flux $\geq$ (a) $10 \mathrm{~kg} \mathrm{~m}^{-1} \mathrm{~s}^{-1}$, (b) $100 \mathrm{~kg} \mathrm{~m}^{-1} \mathrm{~s}^{-1}$, and (c) $500 \mathrm{~kg} \mathrm{~m}^{-1} \mathrm{~s}^{-1}$ in magnitude, sampled at $0-2,2-4$, and $4-6 \mathrm{~km}$ and higher than $6 \mathrm{~km}$. The numbers shown in each panel are the coefficients of the fitted exponential function (Eq. 1).

In the updrafts sampled during COPE (Fig. 10b), the maximum, 10, 50, and $90 \%$ vertical velocities increase with height and the observed maximum value is $23 \mathrm{~m} \mathrm{~s}^{-1}$. The minimum vertical velocity in the downdrafts intensifies from -5 to $-10 \mathrm{~m} \mathrm{~s}^{-1}$ with height up to $4 \mathrm{~km}$, then remains similar at 4-6 km. In the updrafts sampled during ICE-T (Fig. 10c), the maximum vertical velocities increase with height from 5.5 to $25 \mathrm{~m} \mathrm{~s}^{-1}$ up to $6 \mathrm{~km}$, then slightly decrease at $6-8 \mathrm{~km}$. The $90 \%$ value increases from 2 to $6 \mathrm{~m} \mathrm{~s}^{-1}$ between 0 and $4 \mathrm{~km}$, then remains similar at higher levels. The 10 and $50 \%$ values do not show an obvious trend with height. In the downdrafts the minimum vertical velocity remains similar below $4 \mathrm{~km}$ and decreases to $-18 \mathrm{~m} \mathrm{~s}^{-1}$ between 4 and $8 \mathrm{~km}$. The 10,50 , and $90 \%$ values tend to decrease or remain similar at lower levels and then increase with height higher up. The peak $\left(\sim 25 \mathrm{~m} \mathrm{~s}^{-1}\right)$ and the minimum $\left(\sim-18 \mathrm{~m} \mathrm{~s}^{-1}\right)$ vertical velocities are observed at 4-6 and 6-8 km, respectively.

To summarize, the observed vertical velocity in the drafts varies differently with height in the three field campaigns. Stronger downdrafts are often observed in $\mathrm{HiCu}$ and $\mathrm{COPE}$ compared to those in ICE-T. The weak, moderate, and strong drafts have similar variations with height, but the magnitudes are the smallest when including all the drafts and become larger if the weak drafts are excluded. The 10, 50, and $90 \%$ vertical velocities in updrafts and downdrafts over the tropical ocean (ICE-T) observed in this study generally have similar magnitudes to those shown in previous studies (e.g., LeMone and Zipser, 1980; Lucus et al., 1994). But strong updrafts (downdrafts) in excess of $20 \mathrm{~m} \mathrm{~s}^{-1}\left(-10 \mathrm{~m} \mathrm{~s}^{-1}\right.$ ) are also observed in this study, which were rarely reported in previous aircraft observations. This finding is consistent with recent remote sensing observations (e.g., Heymsfield et al., 2010). The updrafts and downdrafts in convective clouds over land shown in this study $(\mathrm{HiCu})$ are weaker than those shown by Byers and Braham (1949) and Heymsfield et al. (2010), possibly because the clouds sampled in $\mathrm{HiCu}$ were isolated convective clouds over the High Plains, which apparently differ from deeper convective clouds at lower elevations.

Figure 10d-f show the profiles which the air mass flux statistics for the drafts sampled during the three field campaigns. As expected, the absolute values of the air mass flux are relatively small if all the drafts are included (dotted boxes) and become larger if the drafts with relatively small air mass flux are excluded. However, the variations of the observed air mass flux with height are similar for the three different definitions in each panel. As determined by the three thresholds, the minimum absolute values in the solid boxes are about 10 times smaller than those in the dashed boxes and about 50 times smaller than those in the dotted boxed. 

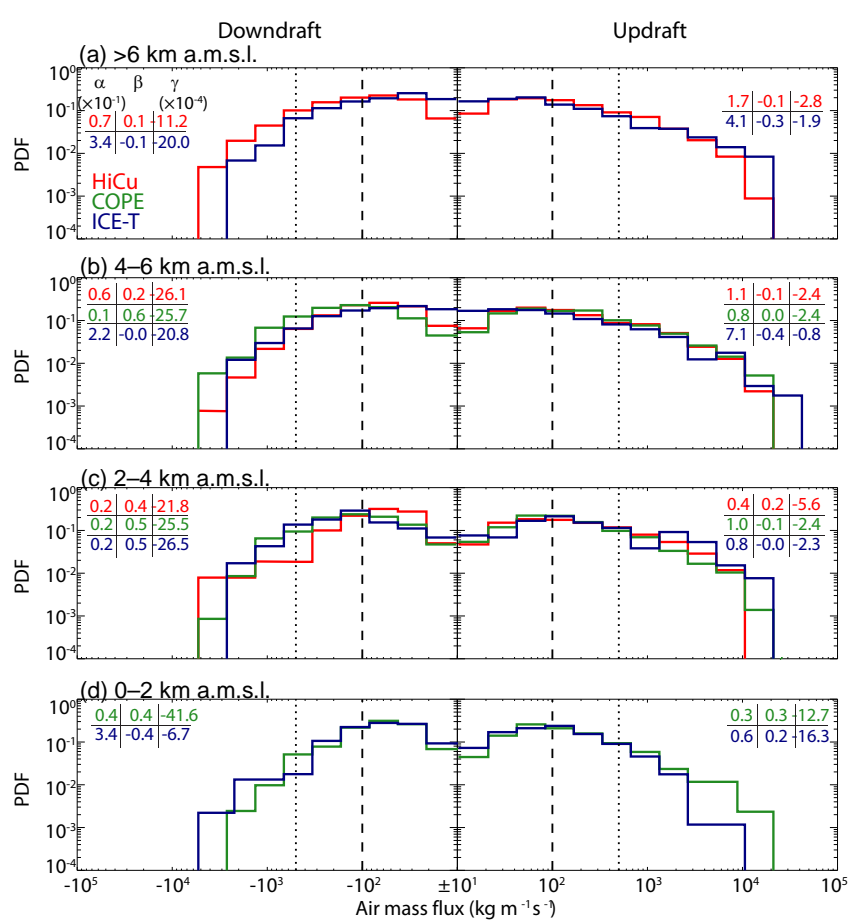

Figure 9. PDFs of the air mass flux for the updrafts and downdrafts sampled at $0-2,2-4$, and $4-6 \mathrm{~km}$ and higher than $6 \mathrm{~km}$. The three thresholds of the air mass flux $\left( \pm 10, \pm 100\right.$, and $\left.\pm 500 \mathrm{~kg} \mathrm{~m}^{-1} \mathrm{~s}^{-1}\right)$ are shown by the solid (overlaps with the central $y$ axis in each panel), dashed, and dotted lines. The numbers shown in each panel are the coefficients of the fitted exponential function (Eq. 1).

For the 10, 50, $90 \%$, and the maximum absolute values, the differences among the three types of boxes become smaller. The observed air mass flux varies with height differently for the three field campaigns and does not have an obvious trend with height. For updraft, the observed maximum air mass flux is on the order of $10^{4} \mathrm{~kg} \mathrm{~m}^{-1} \mathrm{~s}^{-1}$, and the median values for the three different types of boxes are typically $\sim 100$, $\sim 200$, and $\sim 1000 \mathrm{~kg} \mathrm{~m}^{-1} \mathrm{~s}^{-1}$. The observed air mass flux in the downdrafts is a few times smaller in magnitude than those in the updrafts, but extreme downdrafts on the order of $10^{4} \mathrm{~kg} \mathrm{~m}^{-1} \mathrm{~s}^{-1}$ could be observed in some specific cases. Compared to previous studies, the air mass flux in this study shows similar magnitudes, but the vertical dependences are different. Lucas et al. (1994) show that the convection off tropical Australia intensified with height from 0 to $3 \mathrm{~km}$, then weakened with height in terms of air mass flux. Anderson et al. (2005) show that updrafts and downdrafts over the tropical Pacific Ocean intensified with height up to $4 \mathrm{~km}$, then weakened at higher levels. In contrast, this study shows that the strongest updrafts and downdrafts in terms of air mass flux were observed at higher levels.
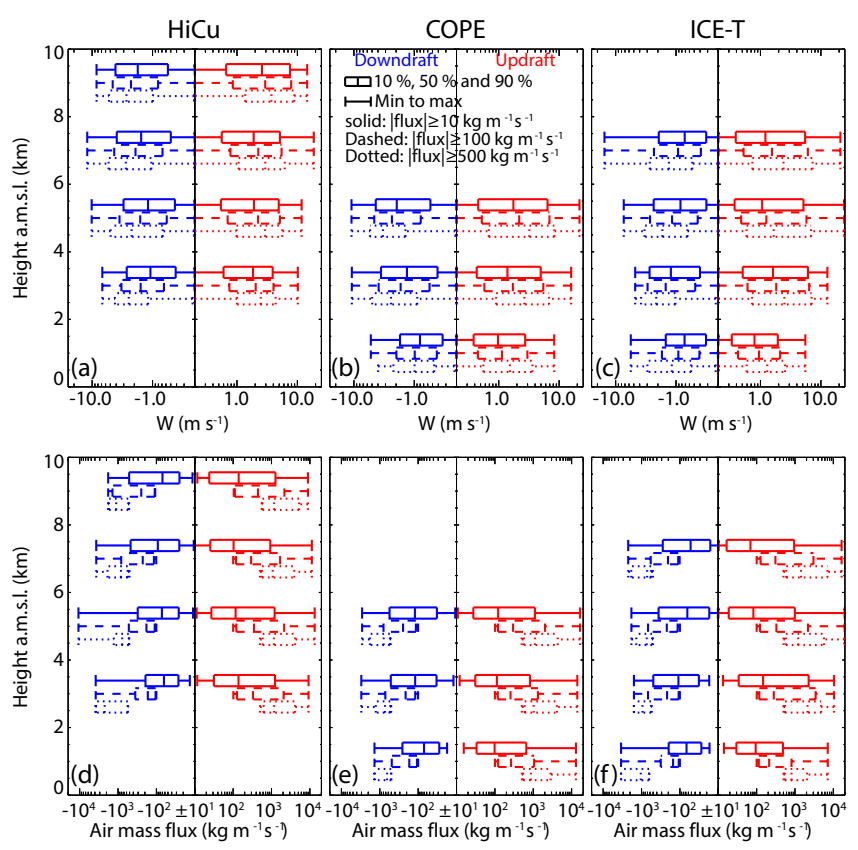

Figure 10. Profiles of (a-c) the vertical velocity and (d-f) air mass flux for all the updrafts and downdrafts sampled at $0-2,2-4,4-6$, $6-8$, and $8-10 \mathrm{~km}$. The dotted, dashed, and solid boxes represent the drafts with air mass flux $\geq 10,100$, and $500 \mathrm{~kg} \mathrm{~m}^{-1} \mathrm{~s}^{-1}$ in magnitude, respectively.

\subsection{Composite structure of vertical velocity}

Figure 11 shows the composite structure for the updrafts and downdrafts with air mass flux $\geq 10 \mathrm{~kg} \mathrm{~m}^{-1} \mathrm{~s}^{-1}$ as a function of normalized scale. The 0 and 1 coordinates on the $x$ axis indicate the upwind and downwind sides of the draft, respectively, such that the draft is centered at 0.5 . Since we do not have continuous penetrations in a single cloud, we have to statistically analyze the evolution of the draft structure. In Fig. 11, we can see that the normalized shape does not change significantly with height, but the observed peak vertical velocity does increase with height for all the three field campaigns. If the magnitude of the vertical velocity is normalized, the structures of the updraft and downdraft at different heights would be very similar. Connecting this figure to the PDFs of diameter (Fig. 4) and air mass flux (Fig. 9), the results show statistically that the drafts were expanding (Fig. 4) and the magnitude of vertical velocity was increasing (Fig. 11), but the air mass flux has no obvious dependence with height (Fig. 9). This reveals the complexity of the evolution of the drafts. Based on our datasets, there could be different possibilities of updraft changes with height: (1) an updraft expanded and the vertical velocity weakened with height; (2) an updraft expanded and the vertical velocity strengthened with height; (3) an updraft divided into multiple updrafts and downdrafts; (4) two updrafts merged and became one updraft. In addition, entrainment-detrainment 

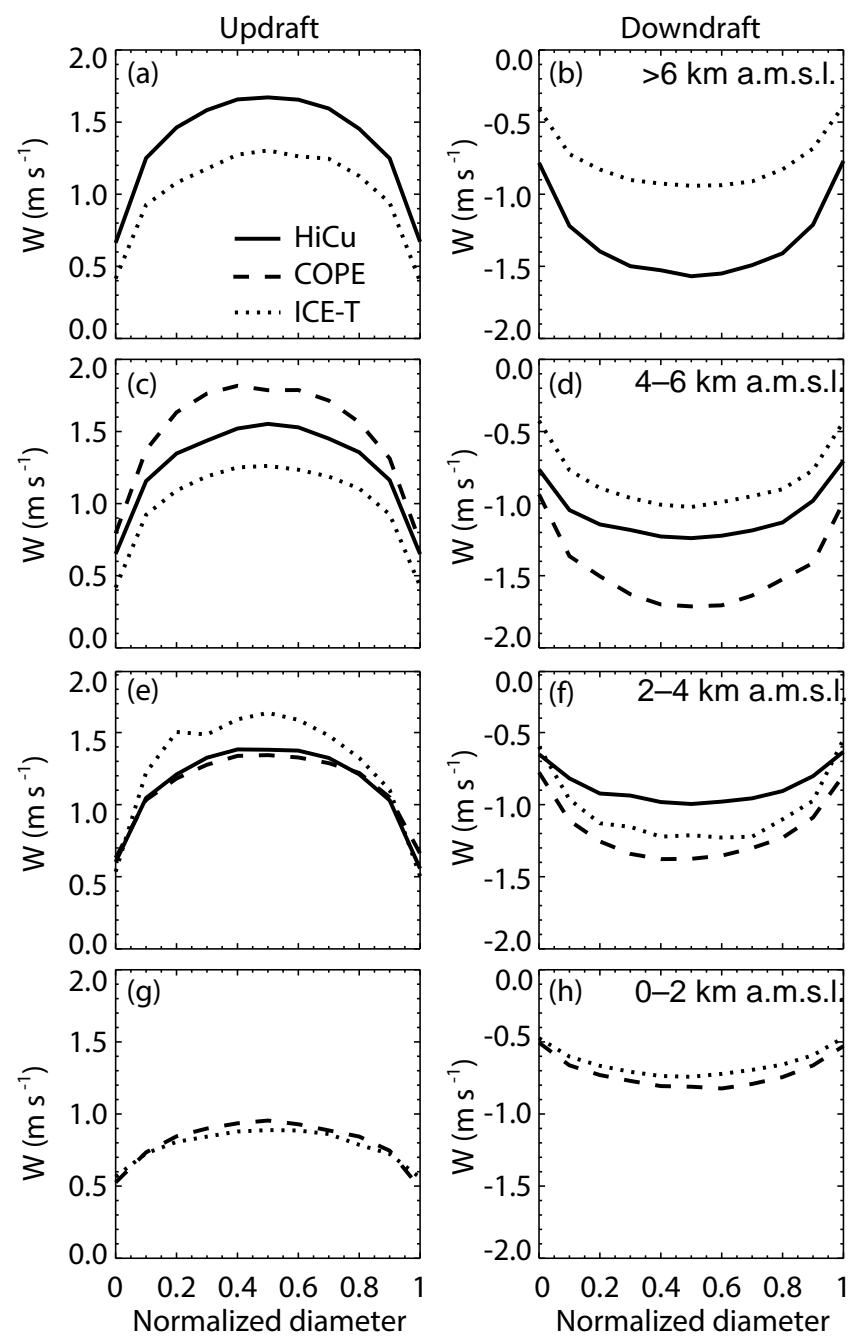

Figure 11. Composite structure of the vertical velocity as a function of the normalized diameter for the updrafts and downdrafts with air mass flux $\geq 10 \mathrm{~kg} \mathrm{~m}^{-1} \mathrm{~s}^{-1}$ in magnitude. The 0 and 1 coordinates on the $x$ axis indicate the upwind and downwind sides of the draft.

and water loading also have important impacts on how drafts change with height within convective clouds.

In this composite analysis based on in situ measurements, the penetration direction has no obvious impact on the vertical velocity structure, whether the aircraft penetrates along or across the horizontal wind (not shown). For convective clouds, wind shear has a large impact on the cloud evolution (Weisman and Klemp, 1982); however, the aircraft data are insufficient to reveal the wind shear impact because each penetration was made at a single level and the aircraft did not always penetrate through the center of the draft. Remote sensing data can be helpful to study the 2-D or 3-D structures of the vertical velocity in convective clouds. For example, airborne radar with slant and zenith or nadir-viewing beams can provide 2-D wind structure in convective clouds (e.g., Wang and Geerts, 2013). Volumetric radar (e.g., Collis et al.,
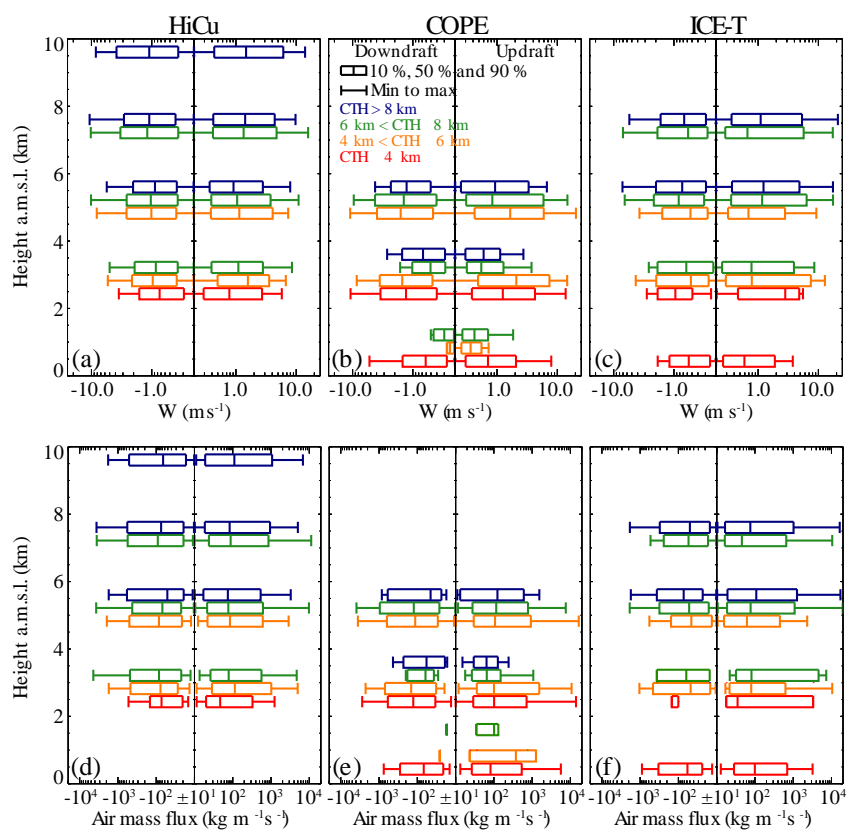

Figure 12. Profiles of (a-c) the vertical velocity and (d-f) the air mass flux for the updraft and downdraft with air mass flux $\geq 10 \mathrm{~kg} \mathrm{~m}^{-1} \mathrm{~s}^{-1}$ in magnitude. The red, orange, green, and blue boxes represent clouds with cloud top heights of $0-4,4-6$, and 6$8 \mathrm{~km}$ and higher than $8 \mathrm{~km}$.

2013; Jorgensen et al., 2000) can provide 3-D structure of air (or hydrometeor) motion. Thus, in situ measurements as well as remote sensing measurements are needed to further analyze the wind shear impact.

\subsection{Vertical air motion characteristics as clouds evolve}

Figure 12 shows the profiles of vertical velocity $(\mathrm{a}-\mathrm{c})$ and air mass flux (d-f) for the updraft and downdraft in the convective clouds with different cloud top heights (CTHs). Here, all weak, moderate, and strong updrafts are included. Different colors represent clouds with different CTHs. These profiles generally reveal the change in vertical velocity and air mass flux as the clouds evolve. The key point presented in Fig. $12 \mathrm{a}-\mathrm{c}$ is that the peak vertical velocity is observed at higher levels as the clouds evolve. For clouds with CTHs lower than $4 \mathrm{~km}$ (red boxes), the maximum vertical velocity is observed at $2-4 \mathrm{~km}$. When the cloud becomes deeper, the observed vertical velocity and air mass flux are stronger at higher levels. The maximum vertical velocity is observed within $2 \mathrm{~km}$ of cloud top; consistent with Doppler velocity images measured by WCR (e.g., Fig. 2b) that show the strongest updraft is typically observed $1-1.5 \mathrm{~km}$ below cloud top. The strongest downdrafts are sometimes observed more than $2 \mathrm{~km}$ below cloud top. The 10 and $50 \%$ values do not have obvious trends as the clouds evolve, possibly because of the increasing contribution from moderate and weak drafts as the clouds become deeper and broader (Figs. 6 and 
7). The observed air mass flux (Fig. 12d-f) has no obvious trend as the clouds evolve, again suggesting multiple factors (e.g., entrainment-detrainment, microphysics) may impact the evolution of these drafts. Since the aircraft provides data from just single-line penetrations, and not 2-D vertical information, additional measurements, including remote sensing measurements, are needed to better understand the evolution of the vertical velocity in convective clouds.

\section{Discussion}

In this study, we provide the statistics of vertical air motion in isolated convective clouds using in situ measurements from three field campaigns. The statistical results suggest that vertical air motions in convective clouds are very complicated and could be affected by many factors.

Microphysics strongly interacts with vertical velocity through different processes, for example, droplet condensation-evaporation, ice nucleation-sublimation, and water loading. Yang et al. (2016) show the liquid water content (LWC) and ice water content (IWC) are both higher in stronger updrafts in developing convective clouds, while the liquid fraction has no obvious correlation with vertical velocity. In mature convective clouds the LWC is also higher in stronger updrafts, but the IWC is similar in relatively weak and strong updrafts. The liquid fraction is correlated to the vertical velocity between -3 and $-8^{\circ} \mathrm{C}$, possibly because the Hallet-Mossop process is more significant in weaker updrafts (Heymsfield and Willis, 2014). Lawson et al. (2015) show that the existence of millimeter drops in the convective clouds can result in fast ice initiation, and the significant latent heat released during the ice initiation process can strengthen the updrafts. In ICE-T and COPE, we also observe many millimeter drops, which may strongly interact with vertical velocity through a fast ice initiation process. However, in some cases, the existence of millimeter drops can result in a significant warm rain process (Yang et al., 2016; Leon et al., 2016), which may weaken the updrafts and result in rapid cloud dissipation.

Entrainment-detrainment also has a strong interaction with vertical velocity. In the analysis above, the downdrafts observed in $\mathrm{HiCu}$ and COPE are stronger than those observed in ICE-T. This may be partly because the ambient relative humidity is low in $\mathrm{HiCu}$ and COPE compared to ICE-T, resulting in a strong evaporation-cooling effect when the ambient air mixes with cloud parcels through lateral entrainmentdetrainment (Heymsfield et al., 1978). Entrainment has impacts on updrafts as well. Recent studies using in situ measurements and model simulations suggest that stronger entrainment may result in weaker updrafts (e.g., $\mathrm{Lu}$ et al., 2016). In this study, we also find that weaker updrafts are associated with stronger entrainment-detrainment using in situ measurements of relative humidity, equivalent potential temperature, droplet concentration, and LWC (not shown). Pre- vious studies (e.g., Heymsfield et al., 1978; Wang and Geerts, 2013) suggest updraft cores unaffected by entrainment may exist in some convective clouds.

Again it is important to be aware of the limitations of using aircraft in situ measurements for this kind of study. More observations (in situ and remote sensing) as well as model simulations are needed to better characterize the vertical air motion in convective clouds and its interactions with microphysics and entrainment-detrainment mixing.

\section{Conclusions}

The vertical velocity and air mass flux in isolated convective clouds are statistically analyzed in this study using aircraft data collected from three field campaigns - $\mathrm{HiCu}$, COPE, and ICE-T - conducted over the midlatitude High Plains, midlatitude coastal area, and tropical ocean. Three thresholds of air mass flux are selected to delineate weak, moderate, and strong draft: 10,100 , and $500 \mathrm{~kg} \mathrm{~m}^{-1} \mathrm{~s}^{-1}$ in magnitude. These definitions only apply for the isolated convective clouds analyzed in this study and are not necessarily appropriate for other convections (e.g., MCSs). The main findings are as follows.

1. Small-scale updrafts and downdrafts in convective clouds are often observed in the three field campaigns. More than 85,90 , and $74 \%$ of the updrafts are narrower than $500 \mathrm{~m}$ in $\mathrm{HiCu}, \mathrm{COPE}$, and ICE-T, respectively, and more than $90 \%$ of the downdrafts are narrower than $500 \mathrm{~m}$ in the three field campaigns combined. These small-scale drafts make significant contributions to the total air mass flux. Updrafts narrower than $500 \mathrm{~m}$ contribute $20-35 \%$ of the total upward flux, and downdrafts narrower than $500 \mathrm{~m}$ contribute $50-65 \%$ of the total downward air mass flux.

2. In terms of the air mass flux, the weak and moderate drafts make an important contribution to the total air mass flux exchange. Generally, the number of drafts increases with cloud diameter. For many narrow clouds, the weak and moderate drafts dominate and contribute most of the total air mass flux. For broader clouds, the stronger updrafts contribute most of the total air mass flux, but the contribution from weak and moderate drafts increases as the cloud evolves.

3. PDFs and profiles of the vertical velocity are provided for the observed drafts. In all the height ranges, the PDFs are roughly exponentially distributed and broaden with height. The observed downdrafts are stronger in $\mathrm{HiCu}$ and COPE compared to ICE-T. Relatively strong updrafts $\left(>20 \mathrm{~m} \mathrm{~s}^{-1}\right)$ were sampled during ICE-T and COPE. The observed updrafts in $\mathrm{HiCu}$ are weaker than previous studies of deeper continental convections, possibly because the clouds sampled in $\mathrm{HiCu}$ were isolated 
convective clouds over the High Plains, which could be different than deeper convective clouds from low elevations.

4. PDFs and profiles of the air mass flux are provided for the observed drafts. The PDFs are similarly exponentially distributed at different heights and have no obvious trend with height. In the updrafts, the observed maximum air mass flux has an order of $10^{4} \mathrm{~kg} \mathrm{~m}^{-1} \mathrm{~s}^{-1}$. The air mass flux in the downdrafts are typically a few times smaller in magnitude than those in the updrafts.

5. The composite structures of the vertical velocity in the updrafts and downdrafts have similar normalized shapes for the three field campaigns: the vertical velocity is the strongest near the center and weakens towards the edges. Statistically, the vertical velocity and diameter were increasing with height, but the air mass flux does not have an obvious trend with height, suggesting that entrainment-detrainment, water loading, and other complicated processes have impacts on the evolution of the drafts.

6. The change in vertical air motion characteristics as the cloud evolves are briefly discussed. Generally, the strongest portion of a draft ascends with height as the cloud evolves. The maximum vertical velocity is observed within $2 \mathrm{~km}$ below cloud top; the downdrafts are sometimes stronger at levels more than $2 \mathrm{~km}$ below cloud top.

The vertical air motion in convective clouds is very complicated and is affected by many factors, such as convection mechanisms, entrainment-detrainment, and microphysics. This study only deals with isolated convective clouds, and there are many limitations of aircraft in situ measurements. More data, including both in situ and remote sensing measurements, are needed to better understand the vertical air motion in convective clouds.

\section{Data availability}

Data collected during ICE-T is available at https://www. eol.ucar.edu/field_projects/ice-t. To request data from $\mathrm{HiCu}$ and COPE, please contact Jeffrey French of University of Wyoming (jfrench@uwyo.edu).
Acknowledgements. This work is supported by National Science Foundation Award AGS-1230203 and AGS-1034858, the National Basic Research Program of China under grant no. 2013CB955802, and DOE Grant DE-SC0006974 as part of the ASR program. The authors acknowledge the crew of NCAR C-130 and University of Wyoming King Air for collecting the data and for providing high-quality products. Many thanks are also extended to Gerald Heymsfield and Scott Collis for their constructive comments.

Edited by: P. Chuang

Reviewed by: G. Haymsfield and S. Collis

\section{References}

Anderson, N. F., Grainger, C. A., and Stith, J. L.: Characteristics of Strong Updrafts in Precipitation Systems over the Central Tropical Pacific Ocean and in the Amazon, J. Appl. Meteorol., 44, 731-738, 2005.

Arakawa, A.: The cumulus parameterization problem: Past, present, and future, J. Climate, 17, 2493-2525, 2004.

Bechtold, P., Bazile, E., Guichard, F., Mascart, P., and Richard, E.: A mass-flux convection scheme for regional and global models, Q. J. Roy. Meteor. Soc., 127, 869-886, 2001.

Byers, H. R. and Braham, R. R.: The Thunderstorm-Report of the Thunderstorm Project. U.S. Weather Bureau, Washington, D.C., June 1949, 287 pp., NTIS PB234515, 1949.

Collis, S., Protat, A., May, P. T., and Williams, C.: Statistics of Storm Updraft Velocities from TWP-ICE Including Verification with Profiling Measurements, J. Appl. Meteoril. Clim., 52, 19091922, 2013.

Del Genio, A. D., Wolf, A. B., and Yao, M.-S.: Evaluation of regional cloud feedbacks using single-column models, J. Geophys. Res., 110, D15S13, doi:10.1029/2004JD005011, 2005.

Donner, L. J., Seman, C. J., Hemler, R. S., and Fan, S.: A Cumulus Parameterization Including Mass Fluxes, Convective Vertical Velocities, and Mesoscale Effects: Thermodynamic and Hydrological Aspects in a General Circulation Model, J. Climate, 14, 3444-3463, 2001.

Giangrande, S. E., Collis, S., Straka, J., Protat, A., Williams, C., and Krueger, S.: A summary of convective-core vertical velocity properties using ARM UHF wind profilers in Oklahoma, J. Appl. Meteorol. Clim., 52, 2278-2295, 2013.

Heymsfield, A. J. and Willis, P.: Cloud conditions favoring secondary ice particle production in tropical maritime convection, J. Atmos. Sci., 71, 4500-4526, 2014.

Heymsfield, A. J., Johnson, P. N., and Dye, J. E.: Observations of Moist Adiabatic Ascent in Northeast Colorado Cumulus Congestus Clouds, J. Atmos. Sci., 35, 1689-1703, 1978.

Heymsfield, G. M., Tian, L., Heymsfield, A. J., Li, L., and Guimond, S.: Characteristics of Deep Tropical and Subtropical Convection from Nadir-Viewing High-Altitude Airborne Doppler Radar, J. Atmos. Sci., 67, 285-308, 2010.

Hildebrand, P. H., Lee, W., Walther, C. A., Frush, C., Randall, M., Loew, E., Neitzel, R., and Parsons, R.: The ELDORA/ASTRAIA Airborne Doppler Weather Radar: High-Resolution Observations from TOGA COARE, B. Am. Meteorol. Soc., 77, 213-232, 1996. 
Hogan, R. J., Grant, A. L., Illingworth, A. J., Pearson, G. N., and O'Connor, E. J.: Vertical velocity variance and skewness in clear and cloud-topped boundary layers as revealed by Doppler lidar, Q. J. Roy. Meteor. Soc., 135, 635-643, 2009.

Houze Jr., R. A. and Betts, A. K.: Convection in GATE, Rev. Geophys., 19, 541-576, 1981.

Igau, R. C., LeMone, M. A., and Wei, D.: Updraft and Downdraft Cores in TOGA COARE: Why So Many Buoyant Downdraft Cores?, J. Atmos. Sci., 56, 2232-2245, 1999.

Ivanova, I. T. and Leighton, H. G.: Aerosol-Cloud Interactions in a Mesoscale Model. Part I: Sensitivity to Activation and CollisionCoalescence, J. Atmos. Sci., 65, 289-308, 2008.

Jorgensen, D. P. and LeMone, M. A.: Vertically Velocity Characteristics of Oceanic Convection, J. Atmos. Sci., 46, 621-640, 1989.

Jorgensen, D. P. and Smull, B. F.: Mesovortex circulations seen by airborne Doppler radar within a bow-echo mesoscale convective system, B. Am. Meteorol. Soc., 74, 2146-2157, 1993.

Jorgensen, D. P., Zipser, E. J., and LeMone, M. A.: Vertical Motions in Intense Hurricanes, J. Atmos. Sci., 42, 839-856, 1985.

Jorgensen, D. P., Shepherd, T. R., and Goldstein, A. S.: A dualpulse repetition frequency scheme for mitigating velocity ambiguities of the NOAA P-3 airborne Doppler radar, J. Atmos. Ocean. Tech., 17, 585-594, 2000.

Khairoutdinov, M. F., Krueger, S. K., Moeng, C.-H., Bogenschutz, P. A., and Randall, D. A.: Large-Eddy Simulation of Maritime Deep Tropical Convection, J. Adv. Model. Earth Syst., 1, 15, doi:10.3894/JAMES.2009.1.15, 2009.

Khelif, D., Burns, S. P., and Friehe, C. A.: Improved Wind Measurements on Research Aircraft, J. Atmos. Ocean. Tech., 16, 860875, 1999.

Kollias, P. and Albrecht, B.: Vertical Velocity Statistics in FairWeather Cumuli at the ARM TWP Nauru Climate Research Facility, J. Climate, 23, 6590-6604, 2010.

Lawson, P. R., Woods, S., and Morrison, H.: The microphysics of ice and precipitation development in tropical cumulus clouds, J. Atmos. Sci., 72, 2429-2445, 2015.

LeMone, M. A. and Zipser, E. J.: Cumulonimbus vertical velocity events in GATE. Part I: Diameter, intensity and mass flux, J. Atmos. Sci., 37, 2444-2457, 1980.

Leon, D., French, J. R., Lasher-Trapp, S., Blyth, A. M., Abel, S. J., Ballard, S., Barrett, A., Bennett, L. J., Bower, K., Brooks, B., Brown, P., Charlton-Perez, C., Choularton, T., Clark, P., Collier, C., Crosier, J., Cui, Z., Dey, S., Dufton, D., Eagle, C., Flynn, M. J., Gallagher, M., Halliwell, C., Hanley, K., Hawkness-Smith, L., Huang, Y., Kelly, G., Kitchen, M., Korolev, A., Lean, H., Liu, Z., Marsham, J., Moser, D., Nichol, J., Norton, E. G., Plummer, D., Price, J., Ricketts, H., Roberts, N., Rosenberg, P. D., Simonin, D., Taylor, J. W., Warren, R., Williams, P. I., and Young, G.: The COnvective Precipitation Experiment (COPE): Investigating the origins of heavy precipitation in the southwestern UK, B. Am. Meteorol. Soc., 97, 1003-1020, doi:10.1175/BAMS-D14-00157.1, 2016.

Lu, C., Liu, Y., Zhang, G. J., Wu, X., Endo, S., Cao, L., Li, Y., and Guo, X.: Improving parameterization of entrainment rate for shallow convection with aircraft measurements and large eddy simulation, J. Atmos. Sci., 73, 761-773, 2016.
Lucas, C., Zipser, E. J., and Lemone, M. A.: Vertical Velocity in Oceanic Convection off Tropical Australia, J. Atmos. Sci., 51, 3183-3193, 1994.

May, P. T. and Rajopadhyaya, D. K.: Vertical Velocity Characteristics of Deep Convection over Darwin, Australia, Mon. Weather Rev., 127, 1056-1071, 1999.

Nicol, J. C., Hogan, R. J., Stein, T. H. M., Hanley, K. E., Clark, P. A., Halliwell, C. E., Lean, H. W., and Plant, R. S.: Convective updraught evaluation in high-resolution NWP simulations using single-Doppler radar measurements, Q. J. Roy. Meteor. Soc., 141, 3177-3189, 2015.

Schmeter, S. M.: Structure of fields of meteorological elements in a cumulonimbus zone, Hydro. Meteor. Serv., Trans. Cent. Aerol. Obs. [Trans. From Russian by Israel Prog. For Sci. Trans., Jerusalem, 1970, 117 pp.], 1969.

Schumacher, C., Stevenson, S. N., and Williams, C. R.: Vertical motions of the tropical convective cloud spectrum over Darwin, Australia, Q. J. Roy. Meteor. Soc., 141, 2277-2288, doi:10.1002/qj.2520, 2015.

Tiedtke, M.: A comprehensive mass flux scheme for cumulus parameterization in large-scale models, Mon. Weather Rev., 117, 1779-1800, 1989.

Tonttila, J., O'Connor, E. J., Niemelä, S., Räisänen, P., and Järvinen, H.: Cloud base vertical velocity statistics: a comparison between an atmospheric mesoscale model and remote sensing observations, Atmos. Chem. Phys., 11, 9207-9218, doi:10.5194/acp-119207-2011, 2011.

Wang, X. and Zhang M.: Vertical velocity in shallow convection for different plume types, J. Adv. Model. Earth Syst., 6, 478-489, 2014.

Wang, Y. and Geerts, B.: Composite Vertical Structure of Vertical Velocity in Nonprecipitating Cumulus Clouds, Mon. Weather Rev., 141, 1673-1692, 2013.

Wang, Z., French, J., Vali, G., Wechsler, P., Haimov, S., Rodi, A., Deng, M., Leon, D., Snider, J., Peng, L., and Pazmany, A. L.: Single aircraft integration of remote sensing and in situ sampling for the study of cloud microphysics and dynamics, B. Am. Meteorol. Soc., 93, 653-668, 2012.

Weisman, M. L. and Klemp, J. B.: The dependence of numerically simulated convective storms on vertical wind shear and buoyancy, Mon. Weather Rev., 110, 504-520, 1982.

Wendisch, M. and Brenguier, J.: Airborne Measurements for Environmental Research: Methods and Instruments, Wiley, 520 pp., 2013.

Wu, J., Del Genio, A. D., Yao, M.-S., and Wolf, A. B.: WRF and GISS SCM simulations of convective updraft properties during TWP-ICE, J. Geophys. Res., 114, D04206, doi:10.1029/2008JD010851, 2009.

Yang, J., Wang, Z., Heymsfield, A. J., and Luo, T.: Liquid/Ice Mass Partition in Tropical Maritime Convective Clouds, J. Atmos. Sci., in review, 2016.

Zipser, E. J., Cecil, D. J., Liu, C., Nesbitt, S. W., and Yorty, D. P.: Where are the most intense thunderstorms on Earth?, B. Am. Meteorol. Soc., 87, 1057-1071, 2006. 